\title{
Hepatitis B immune globulin and HBV-related liver transplantation
}

\author{
Hepatit B immun globulin ve HBV nedeni ile karaciğer transplantasyonu
}

Sinan AKAY, Zeki KARASU

\begin{abstract}
The risk of recurrence of liver cirrhosis and hepatocellular carcinoma due to hepatitis B virus (HBV) infection was $90 \%$ following liver transplantation before 1990's but now we rarely see recurrence due to the highly effective prophylactic treatments. In this review, we discussed the achievements of the prophylactic treatments in patients transplanted for HBV diseases. Options for hyperimmune globulin usage and high genetic barier anti-viral drugs can be used to prevent the recurrence.
\end{abstract}

Keywords: Liver transplant, Hepatitis B hyperimmune globulin, Recurrence

\section{ÖZ}

Hepatit B nedeni ile oluşan karaciğer sirozu veya hepatosellüler karsinoma hastalarında karaciğer transplantasyonu sonrası nüks 1990'lı yıllarda ciddi bir sorun olarak gündemde bulunmaktaydı. Ancak hiperimmun globulin tedavileri ve yüksek direnç bariyerli ilaçlar ile günümüzde nüks sorunu hemen hemen ortadan kalkmıștır. Bu derlemede bu hastalarda kullanılan profikaltik tedavi seçenekleri tartışılmıştır.

Anahtar kelimeler: Karaciğer transplantasyonu, Hepatit B hyperimmun globulin, Nüks

Sinan Akay, Zeki Karasu (丣)

Sub-department of Gastroenterology and Hepatology, Department of Internal Medicine, Ege University, Izmir, Turkey

e-mail: zekikarasu@hotmail.com

\section{Introduction}

More than 350 million chronic carriers of hepatitis B virus (HBV) are present worldwide, and one million deaths occur each year due to cirrhosis and hepatocellular carcinoma [1]. HBV-related end-stage liver disease or hepatocellular carcinoma (HCC), currently represent $5-10 \%$ of cases of liver transplantation (LT) in the West, and is the most common indication for LT in Asia [2]. The risk of hepatitis B viral recurrence, without prophylaxis, following transplantation was reported to be approximately $90 \%$, until 1990's [3]. Presence of delta coinfection and fulminant hepatitis were the factors decreasing the risk of recurrence. After the introduction of passive immunoprophylaxis using parenteral hepatitis B immune globulin (HBIG), post-transplant recurrence of HBV steeply decreased [4]. However, cessation of HBIG therapy resulted in recurrence and graft failure. Within a short period of time, long term prophylaxis with intravenous HBIG became the standard medication for liver transplant recipients infected with HBV [5].

The introduction of nucleoside/nucleotide analogues such as lamivudine brought in another option for posttranplant HBV prophylaxis and for treatment of recurrent disease, but these drugs alone have been inadequate yet to replace HBIG. By using combination prophylaxis with indefinite HBIG and oral antiviral therapy, recurrence rate of hepatitis B can be reduced to $0-10 \%$ [6]. In recent years, new nucleos(t)ide analogues have been approved for the treatment of hepatitis B. Higher efficacy and lower rates of resistance have transformed these new oral medicines such as entecavir and tenofovir into first-line treatments for chronic hepatitis B patients [7]. Post-transplant hepatits B prophylaxis with HBIG chronologically follows high dose HBIG, low dose HBIG, limited-duration HBIG, to no HBIG using combination of NAs or monotherapy with NA with 
high barrier to resistance, with the latter showing excellent clinical outcome.

\section{HBIG alone}

Hepatitis B immune globulin (HBIG) was first introduced in 1974 for passive immunization against infection with hepatitis B virus. HBIG is prepared from plasma donated by individuals with high titers of anti-HBs. Long-term prophylaxis with HBIG is expensive, inconvenient and has been associated with the development of surface antigen mutations [8].

It is accepted that the first dose of HBIG (usually 10 $000 \mathrm{IU}$, ranging $2000-20000 \mathrm{IU}$ ) should be administered at the anhepatic phase during OLT, at a time when major bleeding and oozing has been controlled. In order to prevent reinfection from the extrahepatic reservoirs of virus this protocol is regarded as a must. This initial flooding with anti-HBs, during and immediately after OLT, is followed by daily administration of 400-10,000 units (changes upon protocol) in the first 5 to 10 postoperative days irrespective of actual anti-HBs levels and in some protocols guided by HBs Ag levels (9). Outcome of this regimen is a variable anti-HBs titers among patients, as well as within patient. The high-dose regimens used in US centers have been reported to decrease the rate of recurrent hepatitis B to less than $20 \%$ [10].

For patients with high pre-LT serum titres, neither lamivudine nor HBIG as single agents could prevent graft re-infection. The published experience with lamivudine as single agent prophylaxis is not large. The pitfalls were soon exposed, and the majority of units probably shifted quite quickly from either HBIG or lamivudine as single agents to prophylaxis that combined the two products.

\section{HBIG plus lamivudine}

Since the mechanisms of action and resistance profiles of HBIG and lamivudine are different, combination prophylaxis could potentially reduce the development of resistant mutations and decrease the rate of treatment failures. In addition, combination prophylaxis also creates the possibility of lowering the doses of HBIG, which would result in significant cost reduction.

Angus et al. reported that thirty-one of 32 patients were HBsAg negative, and all 32 patients were HBV DNA negative by PCR followed-up for a mean of 18 months (range, 5 to 45 months)[11]. In this study, HBIG was administered as intramuscular (IM) injections in doses of 400 or 800 IU daily for the first week and monthly thereafter. In this regimen amount of HBIG used was less than one tenth in comparison with most US centers. Longterm administration of low doses of HBIG by the IM route rendered immune prophylaxis more widely available and cost-effective.

Gane et al. confirmed the efficacy of very low-dose HBIG plus lamivudine treatment, in which $85 \%$ of the patients were HBV DNA positive prior to lamivudine treatment. In the post-transplant period, patients received initially 400800 IU daily im HBIG for one week then monthly thereafter. The risk of post-transplant HBV recurrence was found to be $1 \%$ at one year and $4 \%$ at four years [12].

In our country, Turkey, HBV infection is a real public health problem. Almost one-third of the population have antiHBc and almost $4 \%$ of the people are HbsAg carriers [13]. Not surprisingly, HBV cirrhosis is the leading cause of liver transplantation. In adult population, almost half of the liver transplant patients have HBV infection. Considering the economical condition of our country, and because of the high cost and difficulties in availability of HBIG, high dose HBIG regimens would not be convenient for us.

Combination of lamivudine with low dose HBIG was very effective in postransplant HBV prophylaxis, in our earlier study we reported that

the recurrence occurred in about $6 \%$ of patients in a follow-up period of approximately 24 months, in more than 300 adult patients [14]. We obtained similar results with the same protocol in living donor liver transplant recipients, too [15 Anna Lok has rewieved results of 12 studies of prophylactic combination therapy with HBIG and lamivudine, and reported that post-transplant $\mathrm{HBV}$ recurrence was observed in only 7/168 (4\%) patients during a mean follow-up of 13-22 months [16].

The combination of HBIG together with lamivudine has formed the cornerstone of antiviral therapy after surgery in many liver transplant centers worldwide for the best part of the past 15 years. Recent evidence have shown the efficacy of newer and more potent antiviral agents such as entecavir and tenofovir to be effective in the prevention of recurrent HBV-related graft hepatitis in CHB patients after liver transplantation [17].

\section{HBIG plus entecavir}

So far, a regimen completely without HBIG is not 
recommended, but with newer NAs, withdrawal of continuous lifelong administration of HBIG might be feasible. Kim et al retrospectively assessed the clinical outcomes in 154 patients who received entecavir and HBIG after liver transplantation with a median follow-up of 22 months. A total of 5 patients (3.2\%) were diagnosed with $\mathrm{HBV}$ reinfection without entecavir resistance. In 4 of those 5 patients, recurrence of HCC was detected prior to the recurrence of HBV. Recurrent $\mathrm{HCC}$ was found to be an independent risk factor for the recurrence of $\operatorname{HBV}(\mathrm{P}=0.06)$ [18].

$\mathrm{Na}$ et al reported that 4 of $\mathbf{2 6 2}$ recipients who received entecavir combined with HBIG experienced a recurrence of HBV infection after liver transplantation during the median 49-mo follow-up period. They also showed that the incidence of pre-transplant HCC was significantly associated with the recurrence of hepatitis $\mathrm{B}$ [19].

Twenty-six patients who received entecavir plus HBIG after liver transplantation were compared with 63 patients who received LAM and HBIG. No HBV recurrence was detected during the median follow-up period of 25.1 mo in the entecavir group, whereas the HBV recurrence rate was $4 \%$ at 3 years and $6 \%$ at 5 years in the LAM group [20].

\section{HBIG plus tenofovir}

Post-transplant renal dysfunction is commonly seen in liver transplant recipients with long-term utilization of calcineurin inhibitors being a major contributing factor. There may be concern that the use of nucleotides such as adefovir or tenofovir could worsen renal dysfunction. Nephrotoxicity associated with adefovir and tenofovir (both acyclic nucleotide analogs) is related to mitochondrial toxicity in proximal renal tubular cells which manifests as defective proximal phosphate reabsorption and in some instances fullblown Fanconi syndrome.

It was shown that resistance to tenofovir did not emerge in patients in six years of follow-up time after transplant. Studies regarding the efficacy of tenofovir in the prevention of hepatitis B recurrence after liver transplantation are limited.

A small trial reported that four patients received tenofovir plus HBIG with or without entecavir for the prevention of hepatitis B recurrence. After 12 months, no hepatitis B recurrence was observed in these four patients [21].

In a study by Teperman et al, 19 patients were administered emtricitabine/ tenofovir combined with
HBIG post-liver transplantation. No patient experienced a recurrence of $\mathrm{HBV}$ infection at $96 \mathrm{wk}$, and no tenofovir related renal failure was observed in the study [22].

\section{HBIG for a certain period}

Strategies aimed at HBIG discontinuation after a defined period of combination therapy of HBIG and nucleos(t)ide analogues reduce the costs and inconvenience associated with providing HBIG long-term. There is emerging experience examining the efficacy and safety of $\mathrm{HBV}$ prophylaxis using a single nucleos(t)ide for $\mathrm{CHB}$ patients undergoing OLT.

The use of emtricitabine/tenofovir after HBIG discontinuation was evaluated by Teperman et al. In this randomized trial, subjects at a median of 3.4 years after transplant with no evidence of recurrent $\mathrm{HBV}$ and creatinine clearance $>40 \mathrm{ml} / \mathrm{min}$ were treated with combination emtricitabine/tenofovir and HBIG for 24 weeks and then randomized to continue that regimen $(\mathrm{N}=19)$ or discontinue HBIG and continue emtricitabine/ tenofovir alone $(\mathrm{N}=18)$. Of all patients, $47 \%$ had detectable HBV DNA at the time of transplant. At 72 weeks post-randomization, only one patient in the emtricitabine/tenofovir group developed a transient increase in HBV DNA to 314 copies/ml in the setting of poor adherence, and ultimately returned to undetectable levels on follow-up testing. Although $>80 \%$ of participants had baseline mild to moderate renal insufficiency at the outset, no significant change in renal function occurred during tenofovir/ emtricitabine treatment [23].

Cholongitas et al. reported the efficacy of entecavir or tenofovir as monotherapy in preventing HBV recurrence in CHB patients who underwent OLT previously treated with HBIG. Eleven patients with entecavir and 17 patients with tenofovir received HBIG for 6 months. Subsequently, HBIG was discontinued and patients were followed for a median 21 months. Both HBsAg and HBV DNA remained negative in all patients [24].

By considering that $\mathrm{HBV}$ recurrence occurs mostly in the first 3 years (25); after a combination prophylaxis of a 3 years in our center, monoprophylaxis with entecavir or tenofovir is continued by quitting HBIG in patients determined to be HBV DNA negative by PCR in serum and liver tissue. Although there is a limited number of patients (about 30) and the follow-up period is short (approximately 1 year after cessation of HBIG), the recurrence has not developed yet in any of our patients through this approach (unpublished data). 


\section{Regimes without HBIG}

The use of two nucleos(t)ides initiated prior to OLT as prophylaxis without the utilizing HBIG at all was reported by Gane et al. to be effective in preventing recurrent HBV after OLT. The study included 18 CHB patients who had been treated with dual nucleos(t)ides prior to liver transplant that were continued after OLT. During a median 57 months of follow-up, none of the patients developed detectable HBsAg or HBV DNA [26].

Fung et al. studied 362 consecutive CHB patients that were transplanted without utilization of HBIG. Patients were treated either with lamivudine, entecavir, or a nucleoside/nucleotide combination. The median followup length was 53 months. The virological relapse rates $(>1 \log$ increase $\mathrm{IU} / \mathrm{ml})$ at $1,3,5$, and 8 years was 5,10 , 13 and $16 \%$, respectively. The rate of hepatitis B surface antigen seronegativity and hepatitis B virus (HBV) DNA suppression to undetectable levels at 8 years was 88 and $98 \%$, respectively.. The virological relapse rate at 3 years for LAM, ETV, and combination group was 17, 0, and 7\%, respectively $(\mathrm{P}<0.001)$. Forty-two patients had virological relapse, of which 36 had YMDD mutation (31 in the LAM group and 5 in the combination group) [27].

Fung and colleagues have published data on 80 patients undergoing transplant for complications of chronic HBV infection who were maintained on an "HBIG free" regimen consisting of entecavir monotherapy. In this cohort, 33 (41\%) were not on antiviral therapy prior to starting entecavir and only $21(26 \%)$ had undetectable HBV DNA at the time of transplant. Using entecavir monotherapy after transplant, the cumulative rate of HBsAg clearance approached $90 \%$ at one year. Interestingly, a key determinate of HBsAg loss was the pre-transplant quantitative $\mathrm{HBsAg}$ level such that those with lower HBsAg titers $(<3 \log \mathrm{IU} / \mathrm{ml})$ had a significantly higher rate of HBsAg seroconversion at one year $(90 \%$ vs. $74 \%$, $\mathrm{p}=0.025$ ). In those with persistent or recurrent HBsAg, the pretransplant median HBsAg titers were also shown to be significantly higher than in those without persistence/ recurrence. Interestingly, low pre-transplant HBV DNA levels alone were not significantly associated with HBsAg loss, however, when a low HBV DNA $(<5 \log$ copies $/ \mathrm{ml})$ was paired with a low HBsAg level $(<3 \log \mathrm{IU} / \mathrm{ml})$ the cumulative rate of HBsAg seroconversion at 18 months was $100 \%[7]$.

There are ten case series involving 237 patients utilizing dual antiviral therapy. The mean rate HBsAg reappearance was $5.1 \%$ (range $0-14.1 \%$ ). Virological recurrence characterized by detectable HBV DNA was rare, occurring in only one patient who was noncompliantwith tenofovir and emtricitabine [28].

A conceivable risk with using a single oral antiviral for prophylaxis is the emergence of viral resistance. Use of drugs with a high genetic barrier to resistance such as entecavir and tenofovir are superior to drugs such as lamivudine and adefovir, as shown in non-transplant patients [29]. The combination of a nucleotide analogue with an nucleoside analogue has been associated with a very low rate of virologic resistance and the specific combination of lamivudine and adefovir has shown efficacy in the posttransplant setting [30]. The combination of a nucleoside and nucleotide analogue may represent the most effective longterm prophylactic strategy . However, in the aforementioned study by Fung and colleagues that examined the role of entecavir monotherapy after transplant, no resistance mutations were identified after a median follow-up of 26 months [7]. The disadvantages of combination antiviral therapy include higher pill burden (and possibly reduced adherence) and higher cost. The latter issue would depend upon the individual costs of the drugs and this varies considerably by country. Tenofovir-emtricitabine is also an alternative effective combination.

After transplantation, life-long prophylaxis to prevent recurrent hepatitis flares is required. Tendency from using high dose HBIG, low dose HBIG, limited-duration HBIG, to no HBIG using combination of NAs or monotherapy with NA with high barrier to resistance has been observed, with the latter showing excellent clinical outcomes. Cessation of HBIG followed by treatment with new nucleos(t)ide analogues, such as entecavir and tenofovir, is a promising alternative strategy for the prevention of hepatitis B recurrence. The timing for cessation of HBIG is still controversial; however, one year post-transplantation seems to be reasonable.

\section{Key Points}

- Life-long prophylaxis to prevent recurrent hepatitis flares is required in patients with HBV related liver transplantation.

- Hyperimmune globulin combination with Nucleosid Analogs can be a good option.

- Monotherapy with NA with high barrier to resistance has been observed with excellent clinical outcomes.

- However, timing for cessation of HBIG is still a controversial point. 


\section{References}

1. Poland GA, Jacobson RM. Clinical practice: prevention of hepatitis B with the hepatitis B vaccine. N Engl J Med 2004; 351: 2832-38.

2. Kim WR, Terrault NA, Pedersen RA, et al. Trends in waiting list registration for liver transplantation for viral hepatitis in the United States. Gastroenterology 2009; 137:1680-6.

3. Villamil FG. Prophylaxis with anti-HBs immune globulins and nucleoside analogues after liver transplantation for HBV infection. J Hepatol 2003; 39: 466-74.

4. Samuel D, Bismuth A, Mathieu D, et al. Passive immunoprophylaxis after liver transplantation in $\mathrm{HBsAg}$ positive patients. Lancet 1991; 337: 813-5.

5: Lauchart W, Muller R, Pichlmayr R. Long-term immunoprophylaxis of hepatitis $\mathrm{B}$ virus reinfection in recipients of human liver allografts. Transplant Proc 1987; 19: 4051-3.

6. Lok A. Prevention of recurrent hepatitis B post-liver transplantation. Liver Transpl 2002; 8: S67-73.

7. Fung J, Cheung C, Chan SC, et al. Entecavir monotherapy is effective in suppressing hepatitis B virus after liver transplantation. Gastroenterology 2011; 141: 1212-9.

8. Previsani N, Lavanchy D, Zuckerman AJ. Hepatitis B. Viral hepatitis. In: Mushawar IK, editor. Perspectives in Medical Virology, vol. 10. Amsterdam: Elsevier, 2004: 31-98.

9. McGory RW, Ishitani MB, Oliveira WM, et al. Improved outcome of orthotopic liver transplantation for chronic hepatitis B cirrhosis with aggressive passive immunization. Transplantation 1996; 61: 1358-64.

10. Terrault NA, Zhou S, Combs C, et al. Prophylaxis in liver transplant recipients using a fixed dosing schedule of hepatitis B immunoglobulin. Hepatology 1996; 24: 1327-33.

11. Angus PW, Mc Caughan GW, Gane EJ, Crawford DH, Harley H. Combination low-dose hepatitis B immune globulin and lamivudine therapy provides effective prophylaxis against posttransplantation hepatitis B. Liver Transpl 2000; 6: 429-33.

12. Gane EJ, Angus PW, Strasser S, et al. Australasian liver transplant study group. Lamivudine plus low-dose hepatitis B immunoglobulin to prevent recurrent hepatitis B following liver transplantation. Gastroenterology 2007; 132: 931-37.

13. Tozun N, Ozdogan O, Cakaloglu Y, et al. Seroprevalence of hepatitis $\mathrm{B}$ and $\mathrm{C}$ virus infections and risk factors in Turkey: a fieldwork TURHEP study. Clin Microbiol Infect 2015 ;21:1020-6.

14. Karasu Z, Ozacar T, Akyildiz M, et al. Low-dose hepatitis B immune globulin and higher-dose lamivudinee combination to prevent hepatitis B virus recurrence after liver transplantation. Antivir Ther 2004 ;9:921-7.

15. Karasu Z, Akyildiz M, Kilic M, et al. Living donor liver transplantation for hepatitis B cirrhosis. J Gastroenterol Hepatol 2007; 22: 2124-9.

16. Wong SN, Chu CJ, Wai CT, et al. Low risk of hepatitis $\mathrm{B}$ recurrence after withdrawal of long-term hepatitis $\mathrm{B}$ immunoglobulin in patients receiving maintenance nucleos $(\mathrm{t})$ ide analogue therapy. Liver Transpl 2007; 13: 374-81.

17 Teperman LW, Poordad F, Bzowej N, et al. Randomized trial of emtricitabine/tenofovir disoproxil fumarate after hepatitis B immunoglobulin withdrawal after liver transplantation. Liver transplantation : official publication of the American
Association for the Study of Liver Diseases and the International Liver Transplantation Society 2013;19:594601.

18. Kim YK, Kim SH, Lee SD, Park SJ. Clinical outcomes and risk factors of hepatitis B virus recurrence in patients who received prophylaxis with entecavir and hepatitis B immunoglobulin following liver transplantation. Transplant Proc 2013; 45: 3052-6.

19. Na GH, Kim DG, Han JH, et al. Prevention and risk factors of hepatitis B recurrence after living donor liver transplantation. J Gastroenterol Hepatol 2014; 29: 151-6.

20. Ueda Y, Marusawa H, Kaido T, et al. Efficacy and safety of prophylaxis with entecavir and hepatitis B immunoglobulin in preventing hepatitis B recurrence after living-donor liver transplantation. Hepatol Res 2013; 43: 67-71.

21. Jiménez-Pérez M, Sáez-Gómez AB, Mongil Poce L, et al. Efficacy and safety of entecavir and/or tenofovir for prophylaxis and treatment of hepatitis B recurrence post-liver transplant. Transplant Proc 2010; 42: 3167-8.

22. Teperman LW, Poordad F, Bzowej N, et al. Randomized trial of emtricitabine/tenofovir disoproxil fumarate after hepatitis B immunoglobulin withdrawal after liver transplantation. Liver Transpl 2013; 19: 594-601.

23. Teperman LSJ, Poordad F, Schiano T, et al. Randomized trial of emtricitabine/tenofovir DF plus/minus HBIG withdrawal in prevention of chronic hepatitis $\mathrm{B}$ recurrence post-liver transplantation: 48 week results. Abstract presented at American Transplant Congress, Philadelphia, 2011.

24. Cholongitas E, Goulis I, Antoniadis N, et al. New nucleos(t) ide analogue monoprophylaxis after cessation of hepatitis $\mathrm{B}$ immunoglobulin is effective against hepatitis B recurrence. Transpl Int 2014;27:1022-8.

25. Roche B, Feray C, Gigou M, et al. HBV DNA persistence 10 years after liver transplantation despite successful anti-HBs passive immunoprophylaxis. Hepatology 2003;38:86-95.

26. Gane EJ, Patterson S, Strasser SI, McCaughan GW, Angus PW. Combination of lamivudine and adefovir without hepatitis B immune globulin is safe and effective prophylaxis against hepatitis $b$ virus recurrence in hepatitis $b$ surface antigen-positive liver transplant candidates. Liver Transpl 2013;19:268-74.

27. Fung J, Chan SC, Cheung C, et al. Oral nucleoside/ nucleotide analogs without hepatitis B immune globulin after liver transplantation for hepatitis B. Am J Gastroenterol 2013;108:942-948.

28. Khemichian S, Hsieh MJ, Zhang SR, Limurti J, Kim J, Fong TL.Nucleoside-nucleotide analog combination therapy is effective in preventing recurrent hepatitis B after liver transplantation. Dig Dis Sci 2015 ;60:2807-12.

39. Liaw YF, Raptopoulou-Gigi M, Cheinquer H, et al. Efficacy and safety of entecavir versus adefovir in chronic hepatitis $\mathrm{B}$ patients with hepatic decompensation: a randomized openlabel study. Hepatology 2011;54:91-100.

30. Lampertico P, Vigano M, Manenti E, Iavarone M, Sablon E, Colombo M. Low resistance to adefovir combined with lamivudine: a 3-year study of 145 lamivudine-resistant hepatitis B patients. Gastroenterology 2007;133: 1445-51. 